\title{
Vaccinations of International Travellers From Greece to Sub-Saharan Africa
}

\author{
Androula Pavli ${ }^{1}$, Paraskevi Smeti ${ }^{1}$, Fotini Antoniadou ${ }^{2}$, Panos Katerelos ${ }^{1}$, Helena C. Maltezou ${ }^{1 *}$ \\ ${ }^{1}$ Travel Medicine Office, Department for Interventions in Health Care Facilities, Hellenic Center for Disease Control \\ and Prevention, Athens, Greece \\ ${ }^{2}$ Regional Department of Public Health of Attica, Athens, Greece
}

Corresponding Author: Helena C. Maltezou, M.D., Department for Interventions in Health Care Facilities, Hellenic Center for Disease Control and Prevention, 3-5 Agrafon Street, Athens, 15123 Greece. Tel: 30-210-5212-175, Fax: 0-210-5212-177, Email: helen-maltezou@ath.forthnet.gr

Received February 17, 2017; Accepted April 12, 2017; Online Published May 31, 2017

\begin{abstract}
Introduction: The number of travellers from Greece who travel to sub-Saharan Africa has increased during the last decade. Our aim in this research was to study vaccination patterns for travellers travelling to sub-Saharan Africa.

Methods: A cross-sectional study was conducted from January 2011 until December 2014 in all (57) public health departments in Greece. Travellers over 18 years travelling to sub-Saharan Africa participated in this study. A standard form was used in order to collect data about travellers' demographics, immunization history and travel information.

Results: During the study period, 1768 travellers (median age: 39.2 years) travelling to sub-Saharan Africa participated. Among them, $69.2 \%$ of them were male and $95.4 \%$ of them had a Greek nationality. Nigeria was their most common destination (15.7\%). Among all the travellers, 56.7\% stayed in urban areas, 57.9\% travelled for less than one month, 58.5\% for work, 29\% for vacation, and $5.8 \%$ for visiting friends and relatives. Furthermore, $79.7 \%, 30.9 \%, 19.7 \%, 16.8 \%$, and $14.1 \%$ received the yellow fever, typhoid fever, tetanus-diphtheria, hepatitis $\mathrm{A}$, and meningococcal vaccines, respectively. The purpose of travelling was statistically significantly associated with gender, nationality, and the duration of travel. Tetanus, hepatitis A \& B, poliomyelitis, rabies and meningococcal vaccines were more commonly recommended for recreational travel, whereas tetanus, hepatitis $\mathrm{A}$, and poliomyelitis vaccines for short-term travellers and typhoid vaccine for long-term travellers.

Conclusion: It can be concluded that vaccination rrecommendations should be improved for the travellers to sub-Saharan Africa. Individualized and more selective pre-travel recommendations are needed taking in consideration the purpose and duration of travel, the area and place of stay.

Keywords: Travellers, Sub-Saharan Africa, Vaccinations, Recommendations
\end{abstract}

Citation: Pavli A, Smeti P, Antoniadou F, Katerelos P, Maltezou HC. Vaccinations of international travellers from Greece to sub-Saharan Africa. Int J Travel Med Glob Health. 2017;5(2):46-52. doi:10.15171/ijtmgh.2017.10.

\section{Introduction}

During that past few decades, international travel has dramatically increased worldwide. The number of international tourists is expected to reach a total of 1.6 billion by the year 2020 . Travel to Africa recorded a growth of $2 \% .{ }^{1}$

International travels to tropical and subtropical countries may increase the risk of exposure to infectious diseases and may facilitate their global spread., ${ }^{2,3}$ Sub-Saharan Africa is one of the most common destinations (26.7\%) where illnesses are acquired by travellers. ${ }^{4}$ A large proportion of imported infectious diseases to developed countries, including Greece, are related to Vaccine-Preventable Diseases (VPDs). ${ }^{5,6}$ VPDs account for $3 \%$ of febrile episodes. According to
GeoSentinel data; typhoid fever, hepatitis A, and influenza A were the most common VPDs. ${ }^{6,7}$ Therefore, vaccine prophylaxis is an important measure of pre-travel advice. Risk assessment is based on travel variants such as destination, purpose, duration, area and place of travel and travellers' variants including age, medical and vaccination history. Recommendation of vaccinations prior to travel is based on risk assessment and includes routine vaccines (vaccines recommended by the national immunization program), required vaccines, according to the International Health Regulation (IHR), and recommended vaccines. ${ }^{8}$ The current study aimed at assessing pre-travel preparation and provision of vaccinations to international travellers from Greece visiting

Copyright $(\odot 2017$ The Author(s). This is an open access article distributed under the terms of the Creative Commons Attribution License (http:// creativecommons.org/licenses/by/4.0), which permits unrestricted use, distribution, and reproduction in any medium, provided the original work is properly cited. 
sub-Saharan Africa.

\section{Methods}

In Greece, pre-travel vaccination prophylaxis is provided according to the national guidelines issued by the World Health Organization, the Hellenic Centre for Disease Control and Prevention, and the US Centers for Disease Control and Prevention guidelines. ${ }^{9-11}$ Routine vaccinations are administered according to the National Vaccination Program of Greece. ${ }^{12}$ These vaccinations include tetanus-diphtheria pertussis, hepatitis $A$, hepatitis $B$, measles-mumps-rubella (MMR), Haemophilus influenza type B, poliomyelitis, meningococcus serotype C, pneumococcus, human papilloma virus, tuberculosis (Bacillus Calmette-Guérin vaccine), influenza (for high-risk groups only), and rotavirus vaccines. Travel medicine services are provided by 57 public health departments which are the only designated yellow fever vaccination centres in the country. Rabies, typhoid, and cholera vaccines are exclusively delivered to these centres. Pre-travel services and vaccinations are not free of charge.

The inclusion criteria for participation in this questionnairebased study ${ }^{13,14}$ included all adult ( $>18$ years old) international travellers who attended to the public health departments travelling to sub-Saharan Africa from January 1, 2011 to December 31, 2014. The exclusion criteria included travelers who were 18 years of age or less and all those travelling to other destinations other than sub-Saharan Africa. The questionnaire included data in relation to travellers' demographics and medical history and travel variants such as age, gender, nationality, medical and immunization history, date of departure, destination, duration and purpose of travel, place (hotel, camping, local people's home), area of stay (urban or rural), and information about travel medicine services (vaccination, malaria prophylaxis and general preventive measures). The definition of urban accommodation was based on the population of the town. A town with population more than $>5000$ people was defined urban, whereas rural accommodation was defined as villages with populations less than 5000 or those areas residing in the countryside. A trip less than 1 month duration was considered as short-term travel, while a trip of over 1 month was defined as a long-term travel.

Documentation about proof of vaccination was provided by travellers. A written consent was requested from all participants.

Statistical analysis was performed using the STATA 8.0 statistical package. Logistic regression was applied in order to investigate the relation between administration of vaccines and travellers' and/or travel characteristics. $P$ values of $<0.05$ were considered as statistically significant. Continuous parameters (e.g. age) were presented by the use of mean \pm standard deviation (SD) and range. The categorical variables (e.g. gender) were presented using frequency tables. The $\chi^{2}$ test examined the statistical differentiation of each vaccination rate (e.g. hepatitis A vaccination rate) among the 2 categories of travel duration: $<1$ month and $\geq 1$ month. The technique of multinomial logistic regression (reference category $=$ visiting friends and relatives [VFRs], method = stepwise, test for entryremoval=likelihood ratio), examined the statistical relation of the - dependent - variable of travel purpose $(1=$ recreation,
2 =work, $3=$ VFRs) with the following - independent variables: gender $(0=$ female, $1=$ male $)$, Greek nationality ( $1=$ yes, $0=$ no), travel duration $(0 \leq 1$ month, $1>1$ month), tetanus - diphtheria vaccination $(1=$ yes, $0=$ no), hepatitis A vaccination $(1=$ yes, $0=$ no), poliomyelitis vaccination $(1=$ yes, $0=$ no), hepatitis $B$ vaccination $(1=$ yes, $0=$ no), MMR vaccination $(1=$ yes, $0=$ no), yellow fever vaccination ( $1=$ yes, $0=$ no), typhoid fever vaccination $(1=$ yes, $0=$ no), meningococcal $(\mathrm{A}, \mathrm{C}, \mathrm{W} 135, \mathrm{Y})$ vaccination $(1=$ yes, $0=$ no), cholera vaccination $(1=$ yes, $0=$ no $)$ and rabies vaccination $(1=$ yes, $0=$ no $)$.

\section{Results}

During the study period, 1768 international travellers visited sub-Saharan Africa. The participation rate among international travellers ranged from $75 \%$ to $80 \%$ per each public health department. The group not participating in the study was similar in terms of age and gender to the participating group. The overwhelming majority (1686 travellers; 95.4\%) were Greek citizens with a mean age of 39.2 years (range: $0-82$ years; SD: 12.8). International travellers sought pre-travel advice at a mean of 20.9 days (range: 0-336 days; SD: 24.2) before their departure. Their travel characteristics are shown in Table 1. Most travelers (1024 travellers; 57.9\%) travelled for short periods of time. Work was the prevalent purpose of travel (1034 travellers; 58.5\%). Most travellers stayed at a hotel (876 travellers; $49.5 \%$ ) and in urban areas (1003 travellers; $56.7 \%)$. Nigeria was the most common destination followed by Kenya, Somalia, Tanzania, and Ghana, (15.7\%, 10.9\%, $8.9 \%, 8.2 \%$, and $6.7 \%$, respectively) (Table 2 ). Travellers VFRs accounted for $5.2 \%$ of all travellers.

Table 3 shows pre-travel vaccination rates. The yellow

Table 1. Travellers' and Travel Characteristics Among 1768 International Travellers From Greece to Sub-Saharan Africa, 2011-2014

\begin{tabular}{llc}
\hline & & No. $(\%)$ \\
\hline \multirow{3}{*}{ Gender } & Male & $1223(69.2)$ \\
& Female & $400(22.6)$ \\
Mean age (y), SD & Unknown & $145(8.2)$ \\
Duration of travel & 39.2 (range 0-82), 12.8 & \\
& $<1$ month & $1024(57.9)$ \\
& $\geq 1$ month & $627(35.5)$ \\
& Unknown & $117(6.6)$ \\
Purpose of travel & Work & $1034(58.5)$ \\
& Recreation & $513(29)$ \\
& Visiting friends and relatives & $102(5.8)$ \\
& Unknown & $119(6.7)$ \\
\hline Place of stay & Hotel & $876(49.5)$ \\
& Local residence & $390(22.1)$ \\
& Ship & $384(21.7)$ \\
& Camping & $24(1.4)$ \\
& Unknown & $94(5.3)$ \\
\hline Area of stay & Urban & $1003(56.7)$ \\
& Urban \& rural & $323(18.3)$ \\
& Rural & $53(3)$ \\
Outdoor activities & Altitude $>3000 \mathrm{~m}$ & $2(0.1)$ \\
Possible contact with & Ynknown & $387(21.9)$ \\
\hline animals & Yes & $152(8.6 \%)$ \\
\hline & & $52(2.9 \%)$ \\
\hline
\end{tabular}


Table 2. Country Destinations to Sub-Saharan Africa Among 1768 International Travellers From Greece, 2011-2014

\begin{tabular}{|c|c|}
\hline Country Name & No. $(\%)$ \\
\hline Nigeria & $277(15.7)$ \\
\hline Kenya & $193(10.9)$ \\
\hline Somalia & $157(8.9)$ \\
\hline Tanzania & $145(8.2)$ \\
\hline Ghana & $119(6.7)$ \\
\hline Congo, Democratic Republic & $87(4.9)$ \\
\hline Ethiopia & $80(4.5)$ \\
\hline Cameroon & $64(3.6)$ \\
\hline Congo (ex Zaire) & $61(3.5)$ \\
\hline Zambia, Democtaric Republic & $49(2.8)$ \\
\hline Senegal & $48(2.7)$ \\
\hline Sudan & $42(2.4)$ \\
\hline Angola & $28(1.6)$ \\
\hline Uganda & $28(1.6)$ \\
\hline Madagascar & $18(1)$ \\
\hline Sierra Leone & $17(1)$ \\
\hline Gabon & $13(0.7)$ \\
\hline Gambia & $12(0.7)$ \\
\hline Mali & $12(0.7)$ \\
\hline Rwanda & $12(0.7)$ \\
\hline Togo & $12(0.7)$ \\
\hline Niger & $9(0.5)$ \\
\hline Benin & $5(0.3)$ \\
\hline Guinea & $4(0.2)$ \\
\hline Liberia & $4(0.2)$ \\
\hline Mauritania & $4(0.2)$ \\
\hline Mozambique & $4(0.2)$ \\
\hline Burkina Faso & $3(0.2)$ \\
\hline Burundi & $2(0.1)$ \\
\hline Guinea-Equatorial & $1(0.1)$ \\
\hline Mauritius & $1(0.1)$ \\
\hline Seychelles & $1(0.1)$ \\
\hline Unspecified sub-Saharan country & $256(14.5)$ \\
\hline
\end{tabular}

fever vaccine was the most frequently administered vaccine (1409 travellers; 79.7\%), followed by typhoid fever vaccine (546 travellers; 30.9\%) and tetanus-diphtheria vaccine (349 travellers; $19.7 \%$ ) respectively. The total number of delivered vaccines was 3420 (1163 routine and 2257 travel vaccines). Side effects as a result of vaccination have been mainly reported in travellers after yellow fever vaccination including increased temperature, in up to $50 \%$ of travellers. Local reaction has rarely been documented $(<1 \%)$ (Public health departments; personal communication).

The purpose of travel was statistically significantly associated with gender, nationality, duration of travel and hepatitis A vaccination (Appendix 1). Travel durations under 1 month are more often seen in recreational travellers compared to VFRs (odds ratio [OR] = 4.418; Table 4; Appendix 2). Female travellers are less frequent among recreational and work travellers compared to VFRs (ORs $=0.483$ and 0.129 , respectively; Table 4; Appendix 2). Foreign citizens are less frequent among recreational and work travellers compared to VFRs (0.142 and 0.151, respectively; Table 4; Appendix 2). Vaccination against hepatitis A was more frequent among recreational travellers compared to VFRs (Table 4) (according
Table 3. Vaccination Rates Among 1768 International Travellers From Greece to Sub-Saharan Africa, 2011-2014

\begin{tabular}{lc}
\hline Vaccines & No. $\mathbf{\%})$ \\
\hline Routine vaccines $^{\text {a }}$ & \\
Tetanus - Diphtheria & $349(19.7)$ \\
Hepatitis A & $297(16.8)$ \\
Poliomyelitis & $280(15.8)$ \\
Hepatitis B & $203(11.5)$ \\
MMR & $25(1.4)$ \\
Influenza & $7(0.4)$ \\
Pneumonococcal & $1(0.1)$ \\
BCG & $1(0.1)$ \\
Travel vaccines & \\
Yellow fever & $1409(79.7)$ \\
Typhoid fever & $546(30.9)$ \\
Meningococcal (A, C, W135, Y) & $249(14.1)$ \\
Cholera & $33(1.9)$ \\
Rabies & $19(1.1)$ \\
Japanese encephalitis & $1(0.1)$ \\
\hline
\end{tabular}

a In accordance with the National Vaccination Program of Greece.

${ }^{b}$ For second destination which was Southeast Asia.

to Appendix 2, no vaccination against hepatitis A was less frequent among recreation travellers compared to VFRs; $\mathrm{OR}=0.304)$. The recommendation of tetanus, hepatitis A \& B, poliomyelitis, rabies and meningococcal vaccines was statistically significantly associated with the purpose of travel (Table 5). These vaccines were more commonly recommended for recreational travellers. Lastly, tetanus, hepatitis $\mathrm{A}$, and poliomyelitis vaccines were more frequently recommended to short-term travellers, whereas typhoid vaccine was recommended to long-term travellers.

\section{Discussion}

Travelling to tropical and subtropical destinations may increase the risk of exposure to infectious diseases including VPDs. ${ }^{3,4,6,10}$ Therefore, vaccination prophylaxis is an important part of pre-travel advice and may contribute to the reduction of the risk of VPDs. However, less than one third of those international travellers who are diagnosed with VPDs during travel, seek pre-travel consultation as shown by the GeoSentinel network data. ${ }^{5}$

During 2011-2014, 1768 international travellers were studied who attended the public health departments. Although the current study represents only those travellers attending these departments and not the Greek travellers, overall during the same period, the number of travellers attending the few travel clinics available in Greece is very limited. The level of travel health counseling performance between the public health departments showed no difference. Those who travel to destinations where yellow fever vaccine is recommended or required, have to attend these departments since they are the only designated yellow fever vaccination centers in Greece. This fact is also true in regards to vaccination against rabies, typhoid, and cholera since these vaccines are also exclusively available at these departments. According to the National Statistics Service, during 2011-2014, 28091 travellers travelled to Africa from Greece and it is estimated that approximately less than $10 \%$ of them sought pre-travel advice, ${ }^{15}$ which is significantly lower compared to the rates of 
Table 4. Purpose of Travel According to Gender, Nationality and Duration of Travel ${ }^{\mathrm{a}}$

\begin{tabular}{|c|c|c|c|c|c|}
\hline & & \multicolumn{4}{|c|}{ Purpose of Travel } \\
\hline & & $\begin{array}{c}\text { Recreation } \\
\text { No. (\%) }\end{array}$ & $\begin{array}{c}\text { Work } \\
\text { No. }(\%)\end{array}$ & $\begin{array}{c}\text { VFRs } \\
\text { No. }(\%)\end{array}$ & $\begin{array}{c}\text { Total } \\
\text { No. }(\%)\end{array}$ \\
\hline \multirow{3}{*}{ Gender $(P<0.001)$} & Female & $189(38.7)$ & $119(12.6)$ & $48(55.8)$ & $356(23.4)$ \\
\hline & Male & $300(61.3)$ & $827(87.4)$ & $38(44.2)$ & 1165 (76.6) \\
\hline & Total & $489(100)$ & $946(100)$ & $86(100)$ & $1521(100)$ \\
\hline \multirow{3}{*}{ Nationality $(P<0.001)$} & Greek & $498(97.1)$ & $1000(96.7)$ & $27(26.5)$ & $1525(92.5)$ \\
\hline & Other & $15(2.9)$ & $34(3.3)$ & $75(73.5)$ & $124(7.5)$ \\
\hline & Total & $513(100)$ & $1034(100)$ & $102(100)$ & $1649(100)$ \\
\hline \multirow{3}{*}{ Duration of travel $(P<0.001)$} & $<1$ month & $421(84)$ & $496(51.5)$ & $47(52.2)$ & $964(62)$ \\
\hline & $\geq 1$ month & 80 (16) & $467(48.5)$ & $43(47.8)$ & $590(38)$ \\
\hline & Total & $501(100)$ & $963(100)$ & $90(100)$ & $1554(100)$ \\
\hline \multirow{3}{*}{ Hepatitis A vaccination $(P<001)$} & No & $354(69)$ & $921(89.1)$ & $90(88.2)$ & $1365(82.8)$ \\
\hline & Yes & $159(31)$ & $113(10.9)$ & $12(11.8)$ & $284(17.2)$ \\
\hline & Total & $513(100)$ & $1034(100)$ & $102(100)$ & $1649(100)$ \\
\hline
\end{tabular}

aultinomial logistic regression.

Table 5. Vaccination Rates According to Purpose and Duration of Travel

\begin{tabular}{|c|c|c|c|c|c|c|c|}
\hline \multirow[b]{2}{*}{ Vaccine } & \multicolumn{4}{|c|}{ Purpose of Travel } & \multicolumn{3}{|c|}{ Duration of Travel } \\
\hline & $\begin{array}{c}\text { Recreation } \\
\text { No. (\%) }\end{array}$ & $\begin{array}{c}\text { Work } \\
\text { No. }(\%)\end{array}$ & $\begin{array}{c}\text { VFRs } \\
\text { No. }(\%)\end{array}$ & $\begin{array}{c}\text { Total } \\
\text { No. }(\%)\end{array}$ & $\begin{array}{l}<1 \text { month } \\
\text { No. }(\%)\end{array}$ & $\begin{array}{l}\geq 1 \text { month } \\
\text { No. }(\%)\end{array}$ & $\begin{array}{c}\text { Total } \\
\text { No. }(\%)\end{array}$ \\
\hline Tetanus - Diphtheria & $150(29.2)$ & $169(16.3)$ & $12(11.8)$ & $331(20.1)$ & $226(22.1)$ & 105 (16.7) & $331(20.0)$ \\
\hline Hepatitis A & $159(31.0)$ & $113(10.9)$ & $12(11.8)$ & $284(17.2)$ & $204(19.9)$ & $80(12.8)$ & $284(17.2)$ \\
\hline Poliomyelitis & $120(23.4)$ & $131(12.7)$ & $8(7.8)$ & $259(15.7)$ & $180(17.6)$ & $82(13.1)$ & 262 (15.9) \\
\hline Hepatitis B & $114(22.2)$ & $78(7.5)$ & $5(4.9)$ & $197(11.9)$ & $131(12.8)$ & $64(10.2)$ & 195 (11.8) \\
\hline MMR & $11(2.1)$ & $12(1.2)$ & $1(1.0)$ & $24(1.5)$ & $16(1.6)$ & $4(0.6)$ & $20(1.2)$ \\
\hline Yellow fever & $420(81.9)$ & $820(79.3)$ & $84(82.4)$ & $1324(80.3)$ & $824(80.5)$ & $493(78.6)$ & $1317(79.8)$ \\
\hline Typhoid fever & $173(33.7)$ & $306(29.6)$ & $25(24.5)$ & $504(30.6)$ & $253(24.7)$ & $252(40.2)$ & 505 (30.6) \\
\hline Meningococcal (A, C, W135, Y) & $99(19.3)$ & $123(11.9)$ & $9(8.8)$ & $231(14.0)$ & $146(14.3)$ & $91(14.5)$ & $237(14.4)$ \\
\hline Cholera & $7(1.4)$ & $21(2.0)$ & $2(2.0)$ & $30(1.8)$ & $13(1.3)$ & $20(3.2)$ & $33(2.0)$ \\
\hline Rabies & $13(2.5)$ & $3(0.3)$ & $1(1.0)$ & $17(1.0)$ & $13(1.3)$ & $3(0.5)$ & $16(1.0)$ \\
\hline
\end{tabular}

$31-52 \%$ reported in other studies. ${ }^{16-19}$ Therefore, as shown by the National Statistics Service data, the number of travellers seeking pre-travel advice is very few.

In the current study, the yellow fever vaccine was the most frequently administered vaccine, which is partially explained by the fact that the public health departments are the only yellow fever vaccination centers in Greece. Yellow fever vaccination is recommended to travellers with no history of previous immunization, either for destinations where yellow fever is endemic or where there is a current epidemic (e.g. recent epidemic in sub-Saharan Africa and current epidemic in Brazil) or for destinations which require a proof of vaccination. Yellow fever infection has recently been documented in travellers. ${ }^{9-11,20}$

The typhoid vaccine was recommended to $30.9 \%$ of the travellers in our study. Typhoid fever was the most common VPD, according to GeoSentinel data which accounts for $47.6 \%$ of them. ${ }^{5,21}$ In Greece, half of the typhoid fever cases notified to the National Surveillance System of Greece (2004-2013), are travel related. ${ }^{6,22}$ However, no typhoid fever cases were reported in the Greek travellers visiting to the sub-Saharan Africa during the study period. ${ }^{22}$ Typhoid vaccination is recommended for high risk travelers in terms of exposure to typhoid, like those travelling for long-periods of time and those visiting friends and relatives. ${ }^{23}$ Although longer duration of stay in typhoid endemic areas increases the risk of acquiring typhoid fever, even during short visits of less than 1 week to hyper-endemic areas, risks may be seen. ${ }^{24,25}$ In this study, the typhoid fever vaccine was delivered to only $40 \%$ of long-term travellers and $24.5 \%$ of VFR travellers travelling to typhoid endemic fever areas. This is while destinations did not include hyper-endemic areas such as the Indian subcontinent. ${ }^{24,25}$ Unfortunately the poor awareness of travellers and the public health professionals about typhoid vaccination recommendations may be related to the low typhoid vaccine uptake, despite national guidelines. ${ }^{13}$ In the present study, hepatitis A vaccination was recommended to travellers with no history of previous immunization or to those with negative anti-HAV testing. However, hepatitis A vaccine was recommended to only $16.8 \%$ of all travellers who travelled to destinations of high endemicity for hepatitis A. This rate is lower compared to that shown in other studies in which hepatitis A constitutes the prevalent vaccine administered to travellers. ${ }^{26}$ Hepatitis A vaccination should be recommended to all those travelling to countries with high or intermediate risks of hepatitis A. ${ }^{27,28}$ Hepatitis A infection constitutes one of the most common VPDs in international travellers. ${ }^{5,6}$ The relative risk of hepatitis A for travellers 
remains significant although there is up to 50 fold decrease of hepatitis A incidence in travellers during the last few years. This is due to the higher rates of pre-travel vaccination. ${ }^{28}$ In the current study the lower vaccination rates may be related to possible prior immunization or decline of vaccination due to last minute travelling.

Hepatitis B is also considered as a common cause of VPDs among international travellers. ${ }^{5}$ In the current study, hepatitis $B$ vaccine was recommended to only $11.5 \%$ of the travellers which was lower compared to the rates of other studies (15\%$44 \%){ }^{29,30}$ These low hepatitis $\mathrm{B}$ vaccination rates may be related to previous immunization of hepatitis $B$ or the poor perception of the risk of hepatitis B infection. ${ }^{12,30}$

Meningococcal vaccine was recommended to $14.1 \%$ of all travellers. Vaccination is generally recommended to travellers such as long-term travellers, expatriates, and those living in close contact with local people. ${ }^{31}$ In the current study, 35.5\% of the travellers stayed in sub-Saharan Africa for over one month and $22.1 \%$ of them stayed with local people. The high costs of vaccinations or travellers' poor awareness about meningitis risk during travel to the meningitis belt in Africa may be the main reasons for poor vaccination rates. ${ }^{32}$

Rabies vaccination was administered to only $0.4 \%$ of all travellers. This was while $8.6 \%$ and $2.9 \%$ of all travellers reported engagement in outdoor activities and possible contact with animals, respectively. Pre-exposure rabies vaccination is recommended to people travelling to rural areas and those engaging in outdoor activities such as bicycling, hiking, camping, backpacking and to children. ${ }^{31}$ Lack of knowledge about the risks of rabies exposure of travellers and travel health consultants may be related to the low vaccination rates against rabies in this study, ${ }^{33,34}$ as well as to last minute travelling. ${ }^{35}$

During this study, vaccination rates against tetanus/ diphtheria which mainly concerned travellers over 18 years, were lower compared to those of a United States study. ${ }^{26}$ The risk of the acquisition of measles increases in people with no history of immunity against MMR and importation of the disease to countries where not endemic. ${ }^{7}$ Previous vaccination through the National Vaccination Program of Greece may be related to these low vaccination rates. ${ }^{12}$ Since the overwhelming majority of the travellers were from the Greek nationality, they had most probably been vaccinated according to the National Vaccination Program in the past.

In terms of purpose of travel, multiple multinomial logistic regressions showed that there is a statistically significant association between gender, nationality and duration of travel. The recommendation of tetanus, hepatitis A \& B, poliomyelitis, rabies and meningococcal vaccines was statistically significantly associated with the purpose of travel and of tetanus, hepatitis A, poliomyelitis and typhoid vaccines with duration of travel. These correlations may have significance for advising future travellers.

The large number of participants studied in this research provided the opportunity to study a great range of travellers' and travel characteristics and to assess travel vaccine recommendations. However, lack of information regarding the travellers' pre-existing immunity against VPDs is considered as a limitation in the current study. A clear strength of this research is the prospective study of a large number of

\section{Research Highlights}

\section{What Is Already Known?}

VPDs constitute a significant proportion of infectious diseases in developed countries. Vaccinations are essential for pre-travel preparations

\section{What This Study Adds?}

Vaccination recommendations for travellers to subSaharan Africa should get improved. Individualized and more selective pre-travel recommendations are needed taking in consideration the purpose and duration of travel, the area and place of stay.

international travellers from 57 Public health departments, which are the designated yellow fever vaccine centers.

\section{Conclusion}

This research is a large prospective study of pre-travel vaccination recommendations to travellers from Greece visiting sub-Saharan Africa. The results of this study emphasizes the need for more selective and individualized vaccination recommendations based on careful risk assessment, taking in consideration not only the travel destination but also other travel characteristics such as duration and purpose of travel, area and place of stay, and travellers activities. Recommendations should be based on each individual's characteristics including previous immunization, age, underlying medical conditions, possible pregnancy and medication. Public health authorities should be looking for developing strategies in order to increase the awareness of travellers and health professionals about travelrelated health risks and their prevention in particular travelassociated VPDs. They should also promote safety, both for the traveller as well as for the community.

\section{Authors' Contributions}

All authors significantly contributed towards this study.

\section{Conflict of Interest Disclosures}

The authors have no conflicts of interest.

\section{Ethical Approval}

An approval for the study was given by the Hellenic Center for Disease Control and Prevention.

\section{Funding/Support}

No funds were received for the study.

\section{References}

1. World Tourism Organization. Annual report 2014. http:// dtxtq4w60xqpw.cloudfront.net/sites/all/files/pdf/unwto_annual_ report_2014.pdf. Accessed November 26, 2016.

2. Khan K, Arino J, HuW, et al. Spread of a novel influenza A (H1N1) virus via global airline transportation. N Engl J Med. 2009;361:212214. doi:10.1056/NEJMc0904559.

3. Freedman DO, Weld LH, Kozarsky PE, et al. Spectrum of disease and relation to place of exposure among ill returned travelers. $\mathrm{N}$ Engl J Med. 2006;354()2):119-30. doi:10.1056/NEJMoa051331.

4. Leder K, Torresi J, Libman MD, et al. GeoSentinel Surveillance 
Network. GeoSentinel surveillance of illness in returned travelers, 2007-2011. Ann Intern Med. 2013;158(6):456-468. doi:10.7326/0003-4819-158-6-201303190-00005.

5. Boggild AK, Castelli F, Gautret P, et al. Vaccine-preventable diseases in returned international travelers: results from the GeoSentinel Surveillance Network. Vaccine 2010;28(46):73897395. doi:10.1016/j.vaccine.2010.09.009.

6. Maltezou HC, Patrinos S, Veneti $L$, et al. Hepatitis $A$ and enteric fever in Greece, 2004-2011: a cross-sectional analysis. Travel Med Infect Dis. 2014;12(2):143-148. doi:10.1016/j. tmaid.2013.10.004.

7. Wilson ME, Weld LH, Boggild A, et al. Fever in returned travelers: results from the GeoSentinel Surveillance Network. Clin Infect Dis. 2007;44:1560-1568. doi:10.1086/518173.

8. Hatz C, Chen LH. Pre-travel consultation. In: Keystone JS, Freedman DO, Kozarsky PE, Connor BA, Nothdurft HD, eds. Travel Medicine. 3rd ed. Spain: Mosby; 2013:77-101.

9. Hellenic Centre for Disease Control and Prevention (KEELPNO). http://www.keelpno.gr/el. Accessed February 16, 2017.

10. World Health Organization. International Travel and Health 2012. http://www.who.int/ith/ITH_chapter_6.pdf?ua=1. Accessed November 26, 2016.

11. Centers for Disease Control and Prevention. http://wwwnc.cdc. gov/travel/destinations/list/. Accessed February 16, 2017.

12. National Vaccination Program for Children and Adolescents (in Greek). https://diavgeia.gov.gr/. Accessed November 26, 2016. Published 2011.

13. Smeti P, Pavli A, Katerelos P, Maltezou HC. Typhoid vaccination for international travelers from Greece visiting developing countries. J Travel Med. 2014;21:99-103. doi:10.1111/jtm.12076

14. Pavli A, Katerelos P, Smeti P, Maltezou HC. Meningococcal vaccination for international travelers from Greece visiting developing countries. Travel Med Infect Dis. 2016;14:261-266.

15. Hellenic Statistical Authority. http://www.statistics.gr/statistics/-/ publication/STO15/. Accessed 12 March, 2016.

16. Hamer DH, Connor BA. Travel health knowledge, attitudes and practices among United States travelers. J Travel Med 2004;11:2326.

17. Van Herck K, Van Damme P, Castelli F, et al. Knowledge, attitudes and practices in travel-related infectious diseases: the European airport survey. J Travel Med. 2004;11:3-8.

18. Wilder-Smith A, Khairullah NS, Song JH, et al. Travel health knowledge, attitudes and practices among Australasian travelers. J Travel Med. 2004;11:9-15.

19. Pavli A, Spilioti A, Smeti P, et al. Vaccination and malaria prevention among international travelers departing from Athens International Airport to African destinations. J Trop Med. 2014;2014:563030. doi:10.1155/2014/563030.

20. World Health Organization. Disease Outbreak News. http://www. who.int/csr/don/22-april-2016-yellow-fever-china/en/. Accessed February 16, 2017.
21. Gunaratnam $P$, Tobin S, Seale H, McAnulty JM. Infectious diseases in returned travelers, NSW, 2010-2011. N S W Public Health Bull. 2014;24:171-175.

22. Hellenic Centre for Disease Control and Prevention (KEELPNO). http://www.keelpno.gr/el. Accessed March 12, 2016.

23. Monge-Maillo B, Norman FF, Pérez-Molina JA, et al. Travelers visiting friends and relatives (VFRs) and imported infectious disease: travelers, immigrants or both? a comparative analysis. Travel Med Infect Dis. 2014;12(1):88-94. doi:10.1016/j.tmaid.2013.07.004.

24. Steinberg EB, Bishop R, Haber P, et al. Typhoid fever in travelers: who should be targeted for prevention? Clin Infect Dis. 2004;39:186-191.

25. Centers for Disease Control and Prevention. http://wwwnc.cdc. gov/travel/yellowbook/2016/infectious-diseases-related-to-travel/ typhoid-paratyphoid-fever. Accessed March 12, 2015.

26. Larocque RC, Rao SR, Lee J, et al. Global TravEpiNet: a national consortium of clinics providing care to international travelers analysis of demographic characteristics, travel destinations, and pre-travel healthcare of high-risk US international travelers, 20092011. Clin Infect Dis. 2012;54(4):455-462. doi:10.1093/cid/ cir839.

27. Steffen R. Changing travel-related global epidemiology of hepatitis A. Am J Med. 2005;118(suppl 10A):S46-S49.

28. Mutsch M, Spicher VM, Gut C, Steffen R. Hepatitis A virus infections in travelers, 1988-2004. Clin Infect Dis. 2006;42:490 497

29. Leggat PA, Zwar NA, Hudson BJ. Travel Health Advisory Group, Australia. Hepatitis B risks and immunisation coverage amongst Australians traveling to Southeast Asia and East Asia. Travel Med Infect Dis. 2009;7(6):344-349. doi:10.1016/j.tmaid.2009.03.008.

30. Zuckerman JN, Hoet B. Hepatitis B immunisation in travelers: poor risk perception and inadequate protection. Travel Med Infect Dis. 2008;6(5):315-320. doi:10.1016/j.tmaid.2008.05.001.

31. World Health Organization. International Travel and Health, http://www.who.int/ith/chapters/ith2012en_chap6.pdf. Accessed Accessed March 12, 2016.

32. Goodman AL, Masuet-Aumatell C, Halbert J, Zuckerman JN. Awareness of meningococcal disease among travelers from the United Kingdom to the meningitis belt in Africa. Am J Trop Med Hyg. 2014;91(2):281-286. doi:10.4269/ajtmh.13-0763.

33. Pavli A, Saroglou G, Hadjianastasiou S, et al. Knowledge and practices about rabies among travel medicine consultants in Greece. Travel Med Infect Dis. 2011;9(1):32-36. doi:10.1016/j. tmaid.2010.11.004.

34. Altmann M, Parola P, Delmont J, et al. Knowledge, attitudes, and practices of French travelers from Marseille regarding rabies risk and prevention. J Travel Med. 2009;16(2):107-111. doi:10.1111/ j.1708-8305.2008.00283.x.

35. Gautret $P$, Parola P. Rabies vaccination for international travelers. Vaccine. 2012;30:126-133. doi:10.1016/j.vaccine.2011.11.007. 
Pavli et al

Appendix 1. Multinomial Logistic Regression; Likelihood Ratio Test ${ }^{\mathrm{a}}$

\begin{tabular}{lccc}
\hline \multirow{2}{*}{ Variable } & \multicolumn{3}{c}{ Likelihood Ratio Test } \\
\cline { 2 - 4 } & Chi-Square & $\boldsymbol{d f}$ & $\boldsymbol{P}$ Value \\
\hline Travel duration & 103.217 & 2 & $<0.001$ \\
Gender & 106.880 & 2 & $<0.001$ \\
Greek nationality & 23.043 & 2 & $<0.001$ \\
Hepatitis A vaccination & 82.278 & 2 & $<0.001$ \\
\hline
\end{tabular}

${ }^{\mathrm{a}}$ Dependent variable: travel purpose (reference category $=\mathrm{VFRs}$ ).

Appendix 2. Multinomial Logistic Regression Table - Parameter Estimates ${ }^{a}$

\begin{tabular}{|c|c|c|c|c|c|c|c|}
\hline \multirow{2}{*}{ Nagelkerke $\mathbf{R}^{2}=0.297$} & \multirow{2}{*}{ B Coefficient } & \multirow{2}{*}{ SE } & \multirow{2}{*}{ Wald Statistic } & \multirow{2}{*}{$P$ Value } & \multirow{2}{*}{$\begin{array}{l}\text { Odds } \\
\text { Ratio }\end{array}$} & \multicolumn{2}{|c|}{ 95\% Cl for Odds Ratio } \\
\hline & & & & & & Lower Limit & Upper Limit \\
\hline \multicolumn{8}{|l|}{ Recreation } \\
\hline Travel duration (<1 month) & 1.486 & 0.284 & 27.326 & $<0.001$ & 4.418 & 2.531 & 7.712 \\
\hline Gender (Female) & -0.727 & 0.274 & 7.053 & 0.008 & 0.483 & 0.282 & 0.826 \\
\hline Greek nationality $(\mathrm{No})$ & -1.952 & 0.417 & 21.862 & $<0.001$ & 0.142 & 0.063 & 0.322 \\
\hline Hepatitis A vaccination (No) & -1.189 & 0.405 & 8.623 & 0.003 & 0.304 & 0.138 & 0.673 \\
\hline Intercept & 2.286 & 0.434 & 27.703 & $<0.001$ & & & \\
\hline \multicolumn{8}{|l|}{ Work } \\
\hline Travel duration (<1 month) & 0.036 & 0.268 & 0.019 & 0.892 & 1.037 & 0.614 & 1.753 \\
\hline Gender (Female) & -2.047 & 0.270 & 57.279 & $<0.001$ & 0.129 & 0.076 & 0.219 \\
\hline Greek nationality (No) & -1.893 & 0.386 & 24.011 & $<0.001$ & 0.151 & 0.071 & 0.321 \\
\hline Hepatitis A vaccination (No) & 0.312 & 0.413 & 0.569 & 0.451 & 1.366 & 0.607 & 3.072 \\
\hline Intercept & 2.933 & 0.434 & 45.747 & $<0.001$ & & & \\
\hline
\end{tabular}

${ }^{\mathrm{a}}$ Dependent variable: travel purpose (reference category = VFRs). 